The Split Fovea Theory and the Leicester Critique: What do the Data Say?

Lise Van der Haegen, Denis Drieghe, Marc Brysbaert

Ghent University, Belgium

Address for Correspondence:

Lise Van der Haegen

Department of Experimental Psychology

Ghent University

Henri Dunantlaan 2

B-9000 Ghent (Belgium)

E-mail: Lise.VanderHaegen@UGent.be

Tel: 32-9-264-94-29 - Fax: 32-9-264-64-96 


\begin{abstract}
According to the Split Fovea Theory (SFT) recognition of foveally presented words involves interhemispheric transfer. This is because letters to the left of the fixation location are initially sent to the right hemisphere, whereas letters to the right of the fixation position are projected to the left hemisphere. Both sources of information must be integrated for words to be recognized. Evidence for the SFT comes from the Optimal Viewing Position (OVP) paradigm, in which foveal word recognition is examined as a function of the letter fixated. OVP curves are different for left and right language dominant participants, indicating a time cost when information is presented in the halffield ipsilateral to the dominant hemisphere (Hunter, Brysbaert, \& Knecht, 2007). The methodology of the SFT research has recently been questioned, because not enough efforts were made to ensure adequate fixation. The aim of the present study is to test the validity of this argument. Experiment 1 replicated the OVP effect in a naming task by presenting words at different fixation positions, with the experimental settings applied in previous OVP research. Experiment 2 monitored and controlled eye fixations of the participants and presented the stimuli within the boundaries of the fovea. Exactly the same OVP curve was obtained. In Experiment 3, the eyes were also tracked and monocular viewing was used. Results again revealed the same OVP effect, although latencies were remarkably higher than in the previous experiments. From these results we can conclude that although noise is present in classical SFT studies without eyetracking, this does not change the OVP effect observed with left dominant individuals.
\end{abstract}

Keywords: interhemispheric transfer; laterality; split fovea theory; word recognition 


\section{The Split Fovea Theory and the Leicester Critique: What do the Data Say?}

When we perceive visual stimuli, input from the left visual field (LVF) is initially projected to the right hemisphere $(\mathrm{RH})$, whereas input from the right visual field (RVF) is sent to the left hemisphere (LH). This well-known organization of the visual system is a consequence of the fact that the fibers from the nasal hemiretina cross at the optic chiasm whereas those from the temporal hemiretina do not (see Gazzaniga, 2000 , for a review).

There has been a lot of debate, however, about what happens in central vision, and what consequences this has for visual word recognition. The issue is whether visual information in the fovea, the center of the visual field that subtends about 3 degrees of visual angle, is split or not. For many years, projection of foveally presented stimuli was thought to be bilateral. According to this vision, the same information is sent to both hemispheres when words are fixated centrally (e.g., Bunt, Minckler, \& Johanson, 1977). However, an increasing number of researchers have reported evidence in favor of the Split Fovea Theory (SFT) (e.g., Brysbaert, 1994a; Brysbaert, 2004; Brysbaert, Vitu, \& Schroyens, 1996; Ellis, Brooks, \& Lavidor, 2005; Harvey, 1978; Haun, 1978; Hunter, Brysbaert, \& Knecht, 2007; Lavidor, Ellis, Shillcock, \& Bland, 2001; Lavidor \& Walsh, 2004; Martin, Thierry, Démonet, Roberts, \& Nazir, 2007). According to this theory, letters presented to each side of the fixation position are projected to the contralateral hemisphere and interhemispheric communication is needed for the recognition of centrally fixated words.

One line of evidence for the SFT came from research on the Optimal Viewing Position (OVP) effect (Brysbaert, 1994a). The OVP effect is obtained when participants are asked to read words at different fixation positions (O’Regan \& Jacobs, 1992). For example, a six-letter word is presented such that the first, the second, the third, the fourth, the fifth, or the sixth letter falls between two vertically aligned fixation lines (Figure 1). Participants are asked to name the word or to perform a lexical decision on the letter string. Generally, processing times are fastest when words are fixated in the 
first half of the word compared to fixations in the second half. More specifically, the fastest reaction times are observed when fixations fall slightly to the left of the word center, whereas words fixated at the last letter position take the longest time to be recognized.

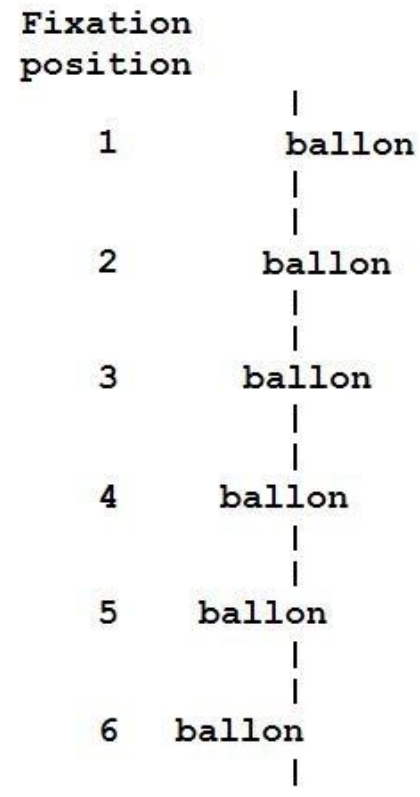

FIGURE 1. Example of the OVP paradigm with the Dutch six-letter word ballon (meaning balloon). On different trials (according to a Latin-square design) the word is presented in such a way that each letter position is fixated. Participants have to name the word as fast as possible.

The OVP effect is the outcome of four factors (Brysbaert \& Nazir, 2005): (1) the first letters contain the most information about the identity of the word; (2) visual acuity decreases when the distance between the fixation location and the letter increases; (3) the eyes tend to land on the first half of the word, so that readers have more practice processing words from this location; and (4) fixating the left side of a word makes most letters fall in RVF and hence most information is sent directly to the $\mathrm{LH}$, the language dominant hemisphere for the majority of readers. ${ }^{1}$

\footnotetext{
${ }^{1}$ About $75 \%$ of left-handed and $95 \%$ of right-handed university students have left hemisphere language dominance; the others have bilateral or right hemisphere dominance for language processing (Hunter \& Brysbaert, 2008b; Knecht et al., 2000).
} 
Evidence for the hypothesis that brain laterality is involved in the OVP-effect was obtained by comparing the OVP effect for participants with left and right hemisphere dominance (Brysbaert, 1994a; Hunter et al., 2007). For left dominant participants, factors 1, 3 and 4 result in a word beginning advantage and, hence, we can expect to find a hefty processing cost when participants are forced to fixate on the last letters. In contrast, for right dominant participants factor 4 results in a word end advantage, so that the OVP curve is expected to be flatter for these individuals. The OVP curve of right dominant participants is not the mirror image of that of the left dominant participants, because laterality is only one of the four factors affecting the curve; the higher informativeness of the word beginning is the same for left and right dominant readers.

To test this prediction, Hunter et al. (2007, Experiment 2) assessed the laterality of speech production in left-handed individuals by means of fMRI. On the basis of this measure, groups of left and right dominant students were identified. These participants were subsequently asked to name four- and seven-letter English words. Stimuli were presented following the OVP paradigm (Figure 1). As predicted by SFT, participants with left hemisphere dominance were faster at naming words fixated at the beginning; in contrast, participants with right hemisphere dominance showed a flat OVP curve (Figure 2).

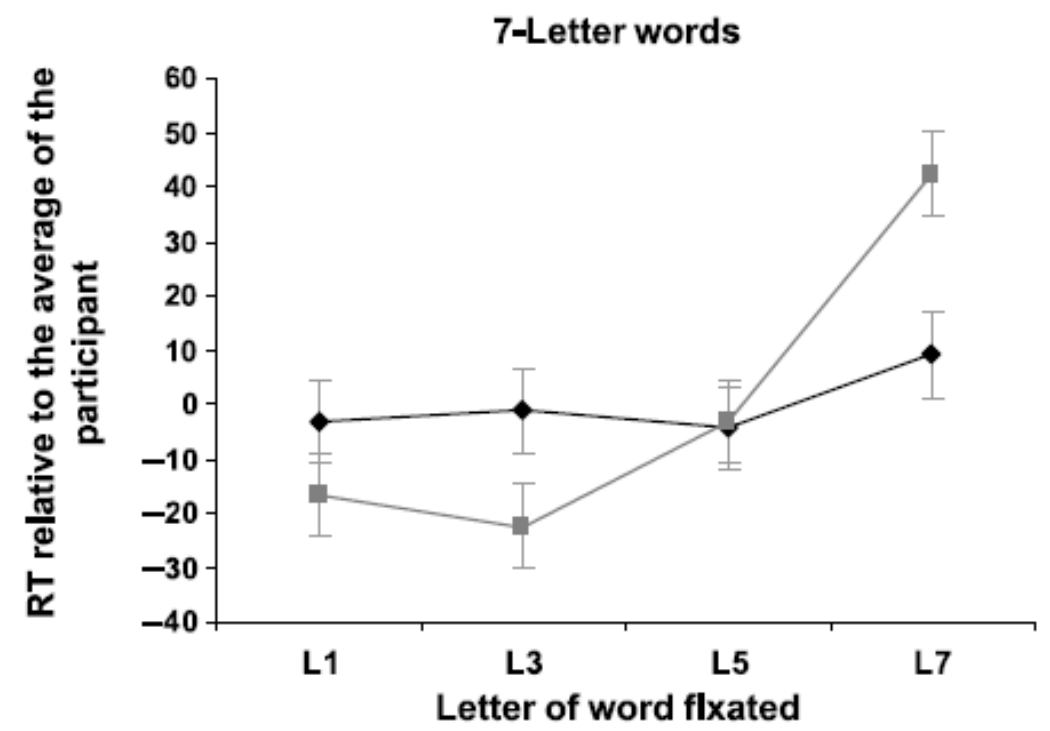

FIGURE 2. OVP curves for naming seven-letter English words in participants with left language dominance (light gray line) and right language dominant participants (dark gray line). The left dominant 
participants show a strong word beginning superiority effect, whereas the right dominant participants show a flat curve. The difference between both groups is in line with SFT. Given that left dominant participants are better at extracting verbal information from RVF, they have an advantage when fixating on the first letters. In contrast, right dominant participants have an advantage for fixations at the end of the word, because they are better at extracting verbal information from LVF. Source: Hunter et al. (2007, Figure 6)

The finding of Figure 2 indicates that interhemispheric transfer is needed for foveal word recognition: There is a time cost when letters of a word are initially sent to the non-dominant hemisphere. If the letters of the foveally presented words had been sent simultaneously to both hemispheres, the OVP would have been the same for left and right language dominant participants.

However, the OVP-evidence for SFT has recently been criticized by a group of researchers working at the University of Leicester (e.g., Jordan \& Paterson, 2009; Jordan, Paterson, \& Stachurski, 2008, 2009). Their objections concern the methodology used in previous SFT research. Four shortcomings have been singled out: (1) the fixation location was not adequately controlled; (2) the size of the foveally presented stimuli was not appropriate; (3) binocular viewing may have contaminated the results; and (4) the naming task may have exaggerated the need for interhemispheric transfer.

The first shortcoming mentioned by the Leicester group concerns the lack of fixation control. Given that SFT sees a sharp divide between LVF and RVF it is critical to know where exactly participants are looking at the moment the word is presented. According to Jordan et al., merely instructing participants to fixate the designated location is insufficient to guarantee proper fixation. Even adding a fixation control task, such as asking participants to name briefly presented digits that appear on some of the trials (e.g., Brysbaert, 1994a; Hunter et al., 2007), does not fulfill the requirement. The only way to properly control fixation positions is by using an eye-tracking device.

The second Leicester criticism involves the fact that the stimuli used in OVP research often exceed the area of foveal vision. In order to increase the precision of the 
measurements, letters in OVP research typically cover an angle between one third and one half of a degree (in most OVP experiments participants are free to choose their position in front of the computer screen, so that there is some variation in the distances between the eyes and the screen). Specifically, with respect to the data reported in Figure 2 it can be objected that the 7-letter words extended an area of more than $1.5^{\circ}$, so that fixations on the first and the last letter made some letters fall outside the bilaterally projecting fovea. As a result, findings such as those of Figure 2 cannot differentiate between interhemispheric transfer in foveal and parafoveal vision. At the same time, Jordan et al. question other research for making their stimuli too small, which in their view magnifies the issue of good fixation control. For instance, they criticized the fiveletter word stimuli used by Lavidor et al. (2001) because these only subtended $0.5^{\circ}$, whereas five letters usually occupy $1.25^{\circ}$ in reading (Rayner \& Pollatsek, 1989). According to Jordan et al., it is unlikely that such small stimuli can be fixated adequately.

A third point of criticism made by the Leicester group concerns the fact that binocular viewing was used during testing. Given that the two eyes may not look at exactly the same location, binocular viewing may provide the cerebral hemispheres with different information from around the fixation location. Such disparities could undermine the conclusions of SFT research.

Finally, Jordan et al. criticized the use of the naming task to investigate SFT. Given that word production is the most lateralized brain function, data with the naming task are likely to result in exaggerated differences between left and the right dominant participants. In their own words (Jordan et al., 2008, p.741): "because speech production in right-handed individuals is lateralized to the $\mathrm{LH}$, using naming as a measure of perceptual performance is likely to produce a spurious advantage for stimuli projected to the LH that does not reflect hemispheric asymmetries in perception."

Although it is tempting to comment on each of the criticisms now, we will refrain from doing so until the General Discussion, as it seems critical first to empirically evaluate the impact of the objections. In particular, although the Leicester 
group has repeatedly shown that fixations are less than adequately controlled by simple instructions, they have never tested the effects of this confound on the OVP curve. Similarly, although they have repeatedly criticized the stimuli for being either too large or too small, they have never examined the consequences of differences in letter size on the OVP effect. So, the first thing to do is to evaluate the Leicester critique properly. Is it the case that the OVP effect for left dominant participants will become flatter when eye fixations are controlled tightly, when the size of the words is made smaller, and/or when participants are forced to look monocularly?

A yes-answer to any of the above questions would force the SFT-proponents to reconsider their position. No-answers to all the above questions would seriously undermine the Leicester critique and would mirror what happened with Jordan's previous critique about inadequate fixation control in studies with parafoveal word presentation in the visual half-field (VHF) paradigm. After having published several papers showing that eye fixation is not well controlled by simply instructing the participants to look at the fixation stimulus in the center of the visual field (e.g., Jordan, Patching, \& Milner, 1998) Jordan and Patching (2005) decided to directly compare free vision and proper fixation control with an eye-tracker. Contrary to their previous claims about the possible dire consequences of sloppy fixation control in the VHF-paradigm, they observed that fixation control had no effect at all on the RVF advantage in the word recognition task they used, forcing them to conclude that (p. 686): "both techniques produced the same pattern of visual field effects, indicating that the demands of fixating a fixed central point do not confound performance with lateralized words." Of course, the main difference between parafoveal and foveal word presentation is that faulty fixations potentially have a much higher impact in the latter condition than in the former. Therefore, it is necessary to test the Leicester critique anew for the OVP curve.

In the experiments reported below we repeated the OVP studies reported by Brysbaert (1994a) and Hunter et al. (2007) and introduced various degrees of fixation control. In addition, we made the stimuli small enough to fit within the foveal area and used monocular viewing. According to the Leicester critique these changes should result in a reduction of the asymmetry in the OVP curve. Because precise assessment of 
language dominance requires fMRI testing of left-handed participants (Hunter \& Brysbaert, 2008b), we limited our studies to right-handed individuals who in addition were right eye dominant (needed because we tracked the right eye). The default expectation for these participants is that they will be left hemisphere dominant and, indeed, none of our participants showed the flat curve typically observed in right dominant participants (Brysbaert, 1994a; Hunter et al., 2007; Hunter \& Brysbaert, 2008a).

\section{Experiment 1}

In the first experiment, we ran a naming task with six-letter words using the experimental settings previously applied. Stimulus size was not adjusted to the boundaries of the foveal visual area, participants were asked to sit at a reading distance of approximately $60 \mathrm{~cm}$, and they were allowed to watch binocularly. As in Brysbaert (1994a) and Hunter et al. (2007), on a limited number of trials a briefly presented digit had to be named to ensure that the participants were fixating properly. As such, we aimed to obtain an OVP curve for left-hemisphere dominant participants similar to the one shown in Figure 2 (light gray line), which could serve as the baseline for Experiments 2 and 3.

Method

\section{Participants}

Participants were twelve students from Ghent University ( 9 female, 3 male; mean age: 21.1). All were native Dutch speakers, had normal or corrected-to-normal vision, and were naive with respect to the purpose of the experiment.

Prior to participation, the students were asked to fill in a questionnaire about their preferences for handedness (Oldfield, 1971), eyedness, earedness and footedness (Porac \& Coren, 1981). They were asked to use a number between -3 and -1 to indicate their degree of left side preference, and a number between +1 and +3 to indicate their 
degree of right side preference (Brysbaert, 1994b). Additionally, participants were asked to perform the Miles (1930) test of eye dominance. In this test participants are asked to look at a distant target through a small opening formed by putting together the thumbs and index fingers of both hands. Then, binocular viewing through the opening is alternated with monocular viewing by each eye. The eye that sees the target when it is opened is selected as the dominant eye. The Miles test was administered to determine the participant's eyedness by means of an unconscious sighting task, which controls for contamination of handedness. ${ }^{2}$ Only students that were right-handed and showed right eye dominance based on the Miles test were accepted for participation ${ }^{3}$. Table 1 shows the mean ratings reported in the questionnaire.

TABLE 1

Mean self-ratings (and SDs) of handedness, eyedness, earedness and footedness as reported by the twelve participants included in each of the Experiments of this study

\begin{tabular}{llll}
\hline Measure & Experiment 1 & Experiment 2 & Experiment 3 \\
\hline Hand & $2,69(0,63)$ & $2,70(0,76)$ & $2,67(0,88)$ \\
Eye & $1,88(1,84)$ & $2,04(1,57)$ & $2,02(1,79)$ \\
Ear & $2,21(0,99)$ & $2,35(0,96)$ & $2,40(1,09)$ \\
Foot & $2,25(0,86)$ & $2,50(0,88)$ & $2,15(1,70)$ \\
\hline
\end{tabular}

Note. $\mathrm{N}=12$ in each Experiment. Scale: $-3=$ strong left preference; $3=$ strong right preference

\section{Materials}

The total stimulus set used in the experiments consisted of 600 words (all were nouns and six letters long) and 60 digits between 1 and 9. The word stimuli were extracted from the CELEX database (Baayen, Piepenbrock, \& Van Rijn, 1993) by using the Wordgen software (Duyck, Desmet, Verbeke, \& Brysbaert, 2004). The digits were

\footnotetext{
${ }^{2}$ For example, participants may indicate a right eye preference for sighting down a rifle, simply because they prefer to have their right hand on the trigger (Porac \& Coren, 1976).

${ }^{3}$ Two students reported to be left eye dominant in the questionnaire. We did not exclude these participants as they showed right eye dominance when performing the more objective Miles test. Moreover, the OVP effect in the repeated measures ANOVA's across participants $(F 1)$ and across items $(F 2)$ for the six fixation positions remained the same without these participants $[F 1(1.88,16.91)=15.64$, $M S E=.00048, p<.001 ; F 2(4.62,1062.39)=7.20, M S E=.0057, p<.001]$
} 
added to ensure that the participants fixated between the two vertically aligned fixation lines.

To mimic the statistical power obtained in Experiments 2 and 3, the stimulus list was divided in two halves. Half of the participants received the first 300 stimuli, the other half received the last 300 stimuli. Thirty digits were included in each list, which is ten percent of the word trials. The words could be presented at six different locations (i.e. with the first, the second, the third, the fourth, the fifth, or the sixth letter between the fixation lines; see Figure 1). To eliminate stimulus confounds, each set of 300 stimuli was divided into six matched groups of 50 words. These groups were matched with respect to word class (all words were nouns), number of syllables, log frequency per million, summed type bigram frequency, and neighborhood size (all $p s>.34$ ). Estimates for the matching process were retrieved from the Wordgen software (Duyck et al., 2004).

A Latin square design was used to ensure that across participants each stimulus was seen in all possible conditions. The full set of stimuli can be found in the Appendix.

\section{Procedure}

All participants were tested individually. Each session lasted approximately 25 minutes. The experiment started with a practice phase, containing 24 six-letter words (four at each of the six possible fixation positions), which did not return in the experimental phase, and 6 digits between 1 and 9 .

The experimenter gave the following instructions (in Dutch) to the participants: "In this experiment, Dutch words will be presented. Name these words as fast and as accurately as possible. The presentation of each word will be preceded by two vertically aligned lines in the middle of the screen. It is of high importance to always fixate between these vertical lines from the moment they appear on the screen until the presentation of the word. From time to time, you will have to name a digit instead of a word. These digits will appear briefly. So, it is important to fixate properly in order to 
be able to name these digits." Participants were also told that they would be paid extra if they named 24 out of the 30 digits correctly. This incentive was added because in a previous experiment without the incentive 8 of the first 15 participants had to be excluded because they made more than $20 \%$ errors on the digit trials; once the incentive was introduced, no participants had to be excluded any more (Van der Haegen, Brysbaert, \& Davis, 2009, Experiment 1).

Stimuli were presented in Courier New font, size 15, on a CRT display. Participants were sitting at a viewing distance of approximately $60 \mathrm{~cm}$, such that the visual area of the words subtended 2.5 degrees.

Each trial started with the presentation of two vertical fixation lines in the middle of the screen. After $400 \mathrm{~ms}$ the word stimulus was presented for $150 \mathrm{~ms}$ between the two lines and participants had to name the word. The fixation lines remained on the screen until the voice key was triggered or until $5000 \mathrm{~ms}$ elapsed. In the digit trials, a digit was presented between the two fixation lines for $80 \mathrm{~ms}$, followed by a mask (\#) also presented for $80 \mathrm{~ms}$. Participants had to name the digit, which was registered by the experimenter. The intertrial interval was $1500 \mathrm{~ms}$.

\section{Results}

Incorrect responses (1.2\%), trials with voice key failures and responses shorter than $200 \mathrm{~ms}$ or longer than $1500 \mathrm{~ms}(1.2 \%)$ were excluded from the analyses. Also, RTs more than 2.5 SDs above or below participant's mean RT in a condition were discarded as outliers $(2.5 \%)$. The mean percentage of errors for the digits was $0.6 \%$; the maximum number of errors made was one digit, so that none of the participants had to be excluded based on the $80 \%$ correct criterion. No participants or items had to be excluded on the basis of the errors or latencies of the word naming task.

Analyses of variance (ANOVA) were run across participants (F1) and across items (F2) for the remaining latencies with fixation position (at letter 1, 2, 3, 4, 5 or 6) 
as a repeated factor. ${ }^{4}$ Due to the positive skewness of the data distribution the ANOVA's were run on the logarithms of the RTs. Greenhouse-Geisser corrections are reported where the assumption of sphericity was violated.

Reaction time analysis. Figure 3 shows the mean response times for the word naming task. The ANOVA of the mean RTs revealed a main effect of fixation position $[F 1(1.93,21.26)=16.59, M S E=.00044, p<.001 ; F 2(4.62,2089.88)=18.07, M S E=$ $.0061, p<.001]$, with the fastest response times when participants fixated at the third letter position $(500 \mathrm{~ms})$ and the slowest response times when they fixated at the sixth letter position (553 ms).

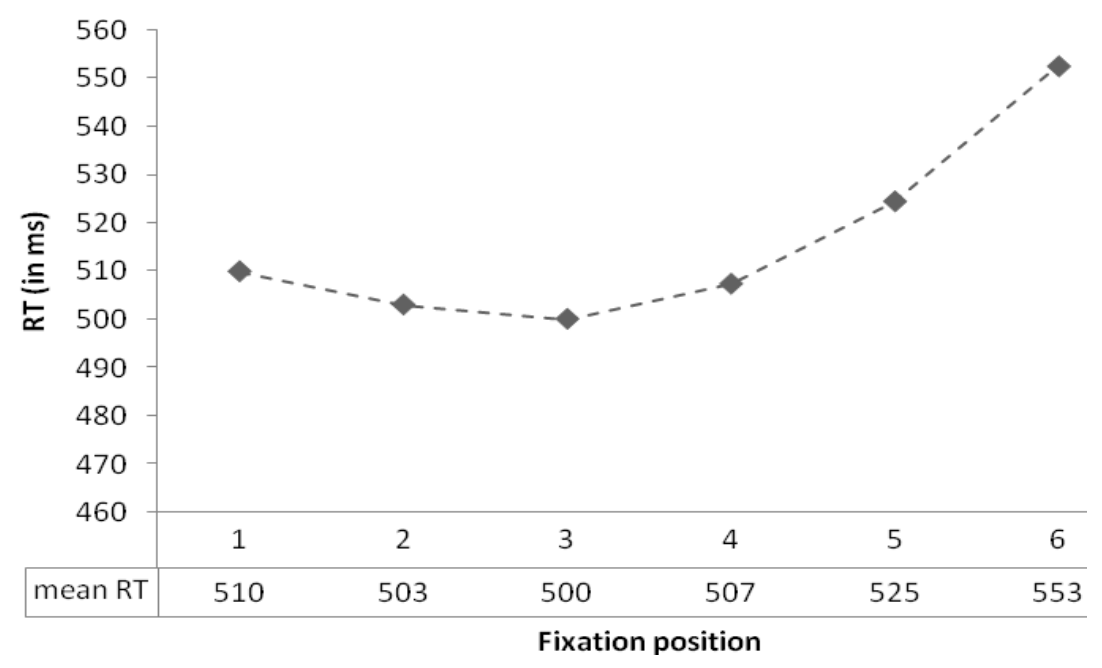

FIGURE 3. Mean response times for the word naming task at the six possible fixation positions in Experiment 1.

Error analysis. Mean percentages of errors were $0.5 \%$ (position 1), $1.2 \%$ (position 2), $0.3 \%$ (position 3), $0.3 \%$ (position 4), 1.2\% (position 5) and 3.7\% (position 6), so lowest at positions 3 and 4 and highest at position 6 , as indicated by the significant main effect of fixation position $[F 1(2.37,26.01)=7.49, M S E=.00057, p<$ $.01 ; F 2(2.86,1714.35)=8.37, M S E=.020, p<.001]$.

\footnotetext{
${ }^{4}$ In psycholinguistic research, effects are usually analyzed both across participants and across items to make sure that any effect observed is not only generalizable to other participants, but also to other items (i.e., is not due to a few deviating items).
} 


\section{Discussion}

Experiment 1 was run to provide a baseline OVP curve for six-letter words, which can be used to compare the data from the further experiments. In this experiment, none of the Leicester critiques was taken into account. We simply copied the parameters of the previous OVP experiments. As expected, the naming data yielded the familiar OVP curve for LH dominant readers, with the shortest latency (500 ms) when the stimuli were fixated at the third letter (the position slightly to the left of the word center) and the longest latency $(553 \mathrm{~ms})$ when the fixation fell on the sixth letter (the last letter of the word).

The difference in naming latency between fixation on the last letter and fixation on the first letter was $43 \mathrm{~ms}$. This compares well with the $23 \mathrm{~ms}$ for 5-letter words and the 55-63 ms for 7-letter words reported by Hunter et al. (2007, Table 2; the OVP is known to become more asymmetric as the words are longer). It also compares well with the estimate of $31 \mathrm{~ms}$ predicted by the SERIOL model of word recognition (Whitney, 2001). This model has been developed on the basis of the data reported in Brysbaert (1994a) and assumes a split fovea with a time cost for interhemispheric communication (see Hunter \& Brysbaert, 2008a for a detailed calculation of the expected values and the application of the model to the Hunter et al., 2007, data).

Now that we have the "traditional" OVP curve, we can assess the impact of the Leicester critiques. Following the SERIOL model, we can even be more specific and predict that the difference between fixation on the first and the last letter will shrink to $13 \mathrm{~ms}$ if there is no need for interhemispheric transfer any more.

\section{Experiment 2}

In Experiment 2, the same task and stimulus set as in Experiment 1 were used. This time, two of the aforementioned shortcomings raised by Jordan et al. $(2008,2009)$ were taken into account. First, stimuli were presented in such a way that they did not 
exceed the three degrees of visual angle of the fovea. The stimulus size of Experiment 1 was kept the same, but the reading distance was adjusted. In this way, the stimulus quality was not degraded because the letters consisted of less pixels. Second, an eyetracking device was used to provide detailed information about the fixation positions of the participants. In the first part of the experiment, participants' dominant right eye was monitored and the stimuli were presented without restrictions. This will be referred to as the EM condition (eye-monitoring condition). In the second part, an eye position contingent stimulus display technique was used. This means that the stimulus was not presented until the participant properly fixated the designated location between the two vertically aligned lines. In the remainder of the text, this condition will be called the EPC condition (eye position contingent). No digits had to be named, and viewing was binocular. If the OVP curve differs from the one observed in Experiment 1, then controlling fixation by means of an eye-tracker is indeed necessary in SFT research.

\section{Method}

\section{Participants}

Sixteen students from Ghent University (13 female, 3 male; mean age: 20.9) were paid for their participation in this experiment. All were native Dutch speakers, had normal or corrected-to-normal vision, and were naive with respect to the purpose of the experiment. None of the participants had taken part in Experiment 1.

As in the previous study, the students were asked to fill out the questionnaire about their preferences for handedness (Oldfield, 1971), eyedness, earedness, footedness (Porac \& Coren, 1981), and they performed the Miles (1930) test. One participant had to be excluded because the Miles test revealed a left eye dominance. Two other participants were removed from the analyses because of unreliable eye movement data due to a large amount of blinking. Finally, a fourth subject was excluded because of poor performance in the naming task relative to the twelve remaining participants (mean percentage of errors: 7.8\%; mean reaction time: $910 \mathrm{~ms}$ ). Excluded participants were replaced by participants who received the same distribution 
of stimuli over conditions, to make sure that we ended with a complete Latin square design. The mean ratings reported in the questionnaire are shown in Table 1.

\section{Materials}

The stimulus set was the same as in Experiment 1. There were no digits included. Again, the stimulus list was divided in two halves. In this experiment, each participant had to name all 600 stimulus words. Half of the participants received the first 300 stimuli in the first part of the experiment (with eye-monitoring) and the last 300 stimuli in the second part (with eye position contingent stimulus presentation). The order of blocks of stimuli was reversed for the other half of the participants. Words were again presented at six different fixation positions (Figure 1). Hence, two factors were manipulated as repeated measures: display type (2 levels: EM vs. EPC) and fixation position (6 levels: at letter position 1, 2, 3, 4, 5 or 6). A Latin square design was used to make sure that each word was presented in each display type condition and at each letter position. Lists were created in the same way as in Experiment 1.

\section{Apparatus}

Eye movements were recorded with a SR Research Eyelink 1000 eye tracking device (Ontario, Canada), which monitored participants' fixation location every millisecond. In the EPC condition stimuli were presented only when the eye-tracker detected 20 consecutive millisecond samples in the area within 0.5 character spaces on each side of the vertical midline. Calibration and validation were carried out with a 9point grid. Eye movements were recorded from the moment the stimulus appeared on the screen. Viewing was binocular throughout the experiment, but eye movements were recorded for the dominant right eye only. A chin rest and a brace at forehead height were used to restrict head movements.

\section{Procedure}


Participants were tested individually. The experiment consisted of two sessions of approximately 45 minutes with a minimum of one week in-between. In the first session, participants were asked to complete the questionnaire described above, followed by the EM condition; the second session consisted of the EPC displays. All participants started with the EM condition, to make this condition as similar as possible to a "traditional" OVP experiment. We did not want participants to start with the EPC condition, because this might have beneficial effects on their performance in the EM condition.

The same instructions (in Dutch) as in Experiment 1 were given to the participants before the beginning of the EM condition. The information that eye movements would be registered and stimuli would appear only if the participants fixated between the two vertical lines was added to the instructions of the EPC phase. Completing the questionnaire, giving the instructions and setting up the eyetracking system took approximately 10 minutes.

Before the experimental trials started, a practice phase was administered, containing twenty-four stimuli (four at each of the six possible fixation positions), which did not return in the experimental phase.

Stimuli were presented in Courier New font, size 15. Participants were sitting at a viewing distance of $101 \mathrm{~cm}$, such that the maximum region of stimulus presentation on either side of the fixation gap was 1.5 degrees of visual angle (i.e. the width of the fovea as suggested by Jordan et al., 2008).

Trials began with a drift correction, followed by a blank screen. After $1000 \mathrm{~ms}$, two vertically aligned lines were presented in the middle of the screen for $400 \mathrm{~ms}$. Thereafter, the stimulus was displayed for $150 \mathrm{~ms}$. In the first experimental session, the stimulus was presented immediately between the two lines; in the EPC session, 20 consecutive millisecond samples from the eye-tracker in the crucial fixation region were required for stimulus presentation. The fixation lines remained on the screen until the voice key was triggered or until 5000 ms elapsed. 
Results

Incorrect responses $(1.5 \%)$ were removed from the reaction time analyses. RTs shorter than $200 \mathrm{~ms}$ or longer than $1500 \mathrm{~ms}$, inadequate voice key registrations $(0.4 \%)$, and RTs above or below 2.5 SDs from the mean RT of a participant's condition (2.2\%) were deleted. Trials on which the first fixation was shorter than $150 \mathrm{~ms}$ (i.e. the duration of stimulus presentation) were removed from the EPC data-analysis (0.7\%). Finally, $0.9 \%$ of the data were lost due to inadequate calibration settings. Eye fixation analyses, latency analyses and error analyses were run on the remaining data.

Eye fixation analysis. Analyses included eye fixation locations during the 150 ms when the stimulus was presented on the screen. Figure 4 shows the distribution and percentages of fixations at the different letter positions for both the EM phase and the EPC phase. The boundaries per letter position were calculated based on the number of pixels covered by the letters.

As can be seen in Figure 4, participants fixated on the letter between the vertical lines on $34.4 \%$ of the trials in the EM condition and on $71.9 \%$ of the trials in the EPC condition. In both conditions, there was a fixation bias towards the left (31.4\% fixations on letter -1 in the EM condition and $16.4 \%$ in the EPC condition). The average deviation from letter position 0 was -0.57 letter positions or -0.16 degrees of visual angle in the EM condition and -0.13 letters or -0.04 degrees of visual angle in the EPC condition.

Notice that $71.9 \%$ of fixations at position 0 in the EPC condition is lower than what could be expected if the stimuli were presented only when participants fixated properly. This is because eye fixations either slightly to the left or to the right of the critical fixation area occasionally included the required 20 millisecond samples in the critical region, hence triggering the stimulus presentation. Indeed, if we made the boundaries of the critical fixation position less strict (up to 0.5 letter positions extra on either side of position 0), fixation accuracy reached $97.9 \%$ in the EPC phase and $61.9 \%$ 
in the EM condition. Although there still is a leftward deviation when corrected, the degree of misfixations is much smaller in the EPC condition.

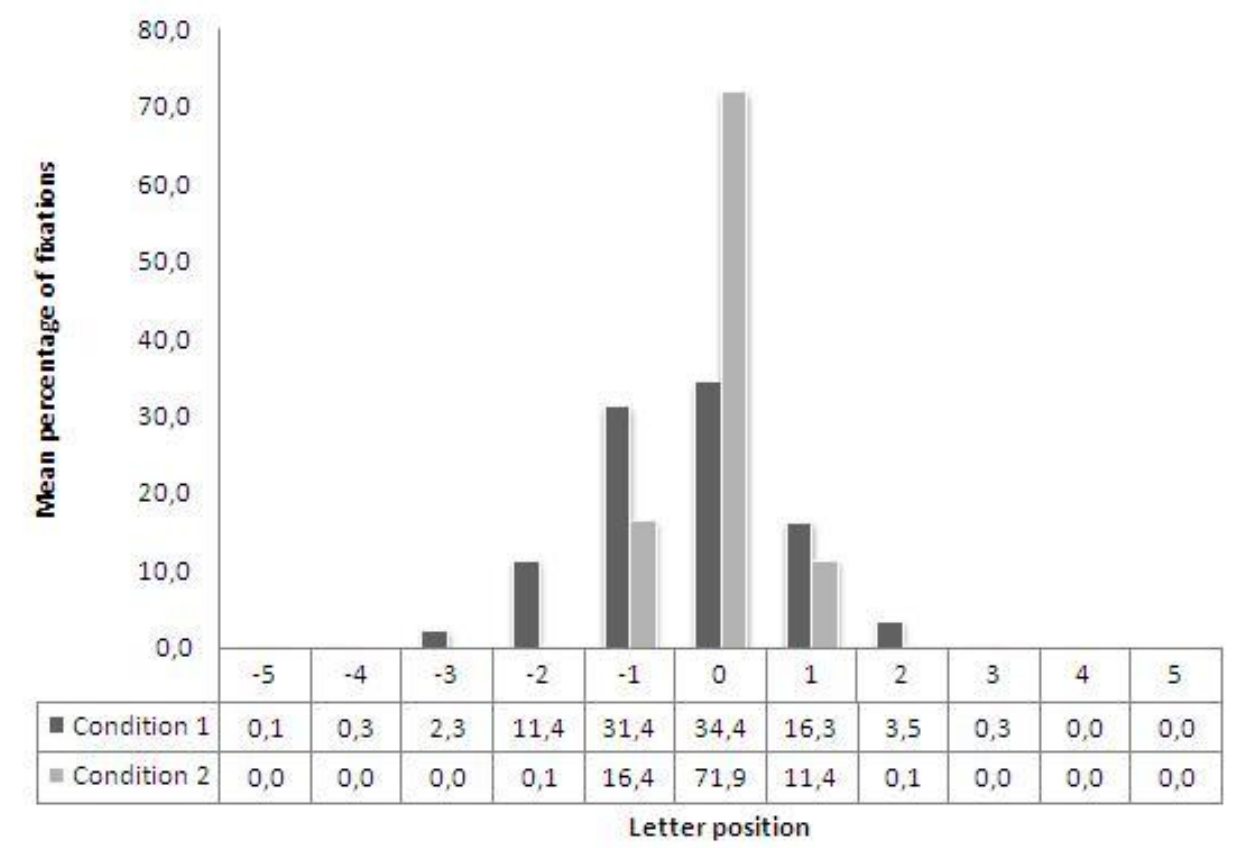

FIGURE 4. Percentages fixation positions at the different letter positions for the two conditions in Experiment 2.

Note. Letter position $-5=$ the leftmost possible fixation position, $0=$ the fixation position between the vertical fixation lines, $5=$ the rightmost possible fixation position; Condition $1=$ eye-monitoring condition; Condition 2 = eye position contingent condition; One letter position subtends $0.27^{\circ}$.

Reaction time analysis. Repeated measures analyses of variance (ANOVA) were run across participants (F1) and across items (F2) with fixation position (6 levels: at letter 1, 2, 3, 4, 5 or 6) and display condition (2 levels: EM vs EPC) as repeated measures. RTs were log-transformed as the distribution of the data was positively skewed. If necessary, Greenhouse-Geisser corrections were applied to correct for sphericity violation.

The ANOVA revealed a main effect of display type $[F 1(1,11)=14.07, M S E=$ $.0038, p<.01 ; F 2(1,319)=311.04, M S E=.0049, p<.001]$, with longer mean latencies in the EPC condition (524 ms) compared to the EM condition (476 ms). The main effect 
of fixation position was also significant $[F 1(2.77,30.48)=21.07, M S E=.00050, p<$ $.001 ; F 2(4.15,1324.98)=15.15, M S E=.012, p<.001]$, with the fastest latencies when fixating at position $3(485 \mathrm{~ms})$ and the slowest latencies for position $6(533 \mathrm{~ms})$. There was no significant interaction between fixation position and display condition $(F \mathrm{~s}<1)$.

As can be seen in Figure 5, the shape of the OVP curves is very similar in the two experimental conditions, as indicated by the non-significant interaction between fixation position and display type. For comparison purposes, the OVP curve of Experiment 1 is also displayed in Figure 5. ANOVA's with fixation position (6 levels: positions 1, 2, 3, 4, 5 or 6) as within-subjects factor and Experiment (2 levels: Experiment 1 vs. Experiment 2 EM condition; or 2 levels: Experiment 1 vs. Experiment 2 EPC condition) as between-subjects factor indicated that there was no significant interaction between experiment and fixation position $(F \mathrm{~s}<1)$.

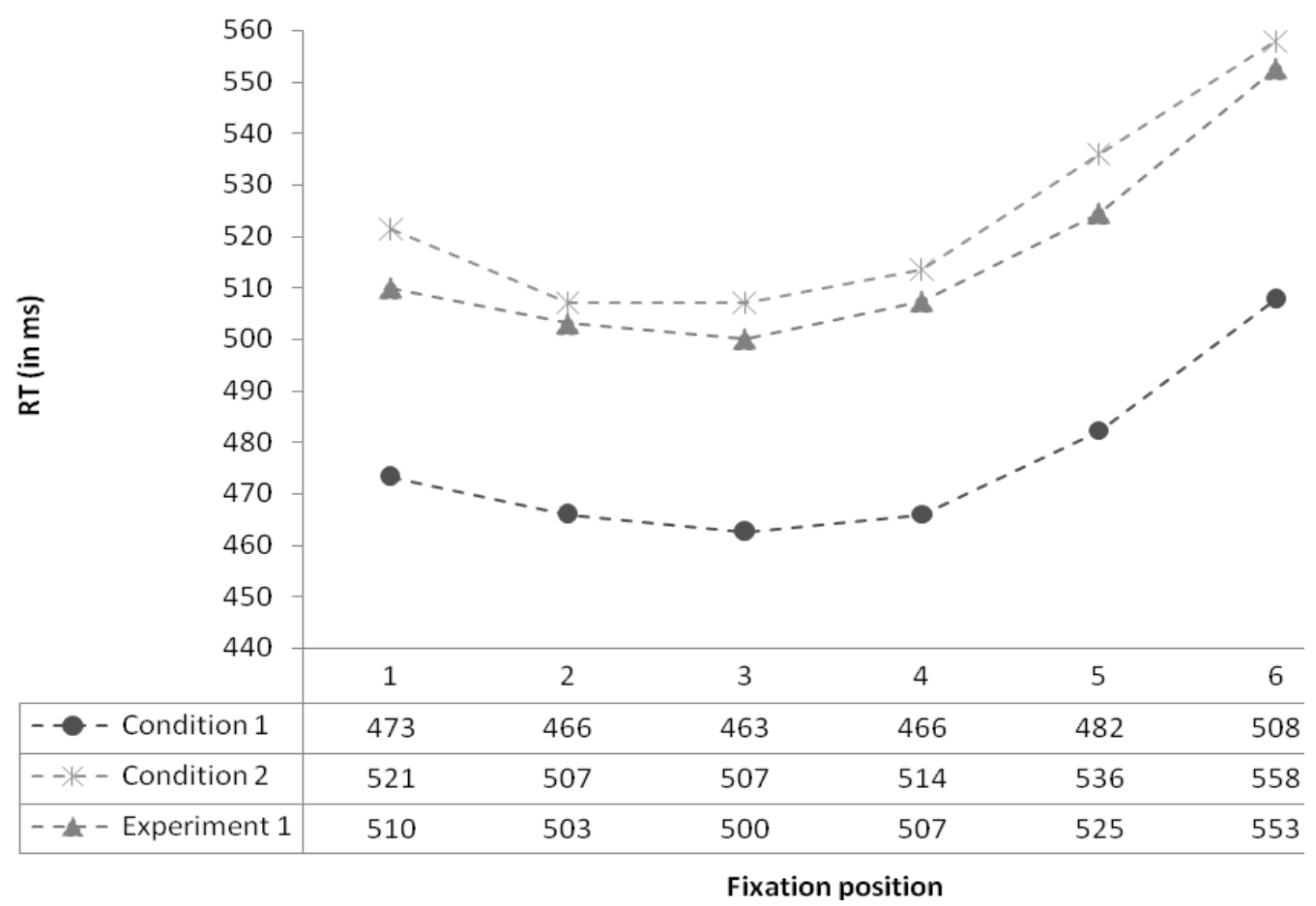

FIGURE 5. Mean response times for the word naming task at the six possible fixation positions and in the two display conditions of Experiment 2 and in Experiment 1. EM = eye-monitoring condition; $\mathrm{EPC}=$ eye position contingent condition. 
Error analysis. Mean percentages of error rates were 1.0\%, 0.2\%, 0.0\%, 0.2\%, $1.0 \%$ and $2.4 \%$ in the EM condition, and $1.7 \%, 0.8 \%, 1.3 \%, 1.7 \%, 1.7 \%$ and $5.7 \%$ in the EPC condition for fixation positions 1, 2, 3, 4, 5 and 6 respectively. The ANOVAs on error rates yielded a main effect of display type $[F 1(1,11)=6.49, M S E=.0011, p<$ $.05 ; F 2(1,539)=17.87, M S E=.015, p<.001]$, with higher error rates in the eye position contingent condition $(2.2 \%)$ than in the eye-monitoring condition $(0.8 \%)$. The main effect of fixation position was also significant $[F 1(1.98,21.79)=8.80, M S E=$ $.0011, p<.001 ; F 2(3.48,1877.76)=10.36, M S E=.020, p<.001]$, with the lowest error rate at position $2(0.5 \%)$ and the highest error rate at position $6(4.0 \%)$. Finally, there was no significant interaction between fixation position and display type $[F 1(2.69,29.56)=1.31, M S E=.00085, p=.29 ; F 2(3.62,1951.55)=1.86, M S E=.019$, $p=.12]$.

\section{Discussion}

In Experiment 2 we replicated Experiment 1 with two major changes. First, the word size was decreased from about $2.5^{\circ}$ to $1.5^{\circ}$, so that the stimulus remained in foveal vision even when fixated on the first or the last letter. Second, participants' eye movements were monitored to examine the alleged confound between fixation position and OVP curve. In the first part of the experiment, the eye movements were simply monitored (EM condition); in the second part, the stimuli were not displayed until the participants fixated appropriately (EPC condition).

As can be seen in Figure 5, none of the changes had any effect on the OVPcurve. In all conditions, naming latencies were the fastest when stimuli were fixated slightly to the left of the word center and slowest at the rightmost fixation position. The difference in naming latency between fixation on the first and the last letter was $35 \mathrm{~ms}$ in the EM condition and $37 \mathrm{~ms}$ in the EPC condition (remember that a difference of 31 ms was expected on the basis of the SERIOL model of word recognition; see the discussion of Experiment 1). Error rates were in line with the latency analysis: most errors were made at position $6(4.0 \%)$ and least errors were made at position $3(0.5 \%)$. 
We also replicated Jordan et al.'s (2009) finding that participants are not always fixating exactly where they have been instructed to if no eye position contingent stimulus presentation is used. On two thirds of the trials they were looking at a different letter position than they were supposed to. Most of these deviations were to the letter position left of the instructed location. Interestingly, the distribution of eye fixations in degrees of visual angle was very similar in our experiment as in Jordan et al. (2009, Figure 3): The vast majority of fixations in both experiments were in the region between $-0.25^{\circ}$ and $+0.25^{\circ}$. A difference between our data and those of Jordan et al. (2009) is that in their experiment the distribution was symmetric whereas in our study there is a bias to the left. This bias remains to some extent in the EPC condition.

When participants look one position to the left of the required location in the OVP paradigm, they look at the blank space before the word when it is presented at position 1 and they look at the second last letter of the word when it is presented at position 6 (Figure 1). The most likely interpretation of this bias is that participants try to optimize their performance. Given that performance deteriorates rapidly for fixations towards the end of the word and changes little for fixations towards the beginning, it is more efficient to look slightly to the left of the fixation location. Forcing participants to look at the required fixation location slightly deteriorates their performance and somewhat increases the left-right asymmetry, as can be seen in Figure 5. As no performance asymmetry was present in Jordan et al.'s (2009) task, participants had no incentive to bias to one or the other side.

As a whole, the eye position contingent stimulus display session was experienced as much more fatiguing by the participants, despite the fact that there was more than a week between the first and the second experimental session. The error rate and the response latencies were significantly higher and we had to exclude 2/16 participants for reasons related to the eye-tracking. The main effect of display type with longer latencies and higher error rates in the EPC condition compared to the EM condition was partially due to the fixation behavior of the participants. On several trials in the EPC condition they had to search for the exact fixation location that would trigger the stimulus display. As such, participants were more insecure about the exact moment 
the stimulus would appear on the screen and were less prepared to respond than in the EM condition.

Most importantly, however, was the observation that despite the eye fixation noise in the EM condition there was no difference in the OVP curves of the two conditions. If anything, the OVP-curve was slightly "clearer" (i.e., a stronger left-right asymmetry and a higher impact of the distance between the extreme letters and the fixation location) in the EPC condition than in the EM condition. This agrees with the claim that the deviations from the intended fixation location induce noise rather than a systematic bias. As mentioned in the Introduction, this was also the conclusion Jordan and Patching (2005) reached on the basis of their VHF-study.

A remaining possibility is that the OVP-effect might be affected by fixation disparities between the two eyes. Eye-movement research in reading has indicated that the eyes are not always moving in a fully yoked way, so that disparities of up to two letter positions are not uncommon (Kirkby, Webster, Blythe, \& Liversedge, 2008). Although these deviations are obtained with moving eyes, Jordan et al. (2008; 2009) conjectured that similar disparities might be present in OVP experiments and might invalidate the conclusions. Therefore, in Experiment 3, we tested the effect of monocular viewing. We also tested whether the fixation control task used in Experiment 1 could reduce the leftward bias observed in the EM condition.

\section{Experiment 3}

Given the results of Experiments 1 and 2, a final experiment was run to test the validity of the Leicester objection that binocular viewing contaminates the results of SFT research. The same displays as in Experiment 2 were used, but viewing in the EPC was monocular (with the dominant eye) instead of binocular. In addition, we added the eye fixation control task of Experiment 1 to the EM condition to see whether this would improve the fixation accuracy. To maximize the comparability of this condition with Experiment 2, we used binocular vision. As in Experiment 2, the EM condition was run 
before the EPC condition and the sessions were run on different days to avoid fatigue effects.

\section{Participants}

Sixteen students from Ghent University (11 female, 5 male; mean age: 20.6) were paid to participate in the experiment. All students were native Dutch speakers, had normal or corrected-to-normal vision, and were naive with respect to the purpose of the experiment. None of them had participated in Experiments 1 or 2.

The data from the questionnaire about preferences for handedness (Oldfield, 1971), eyedness, earedness, and footedness (Porac \& Coren, 1981) can be seen in Table 1. All participants also performed the Miles (1930) test and were confirmed as right eye dominant. Two participants were excluded in the second session because they reported that the task was too difficult and hence the session had to be cancelled. One participant had to be excluded because of an insufficiently corrected vision. The data of one more participant were lost due to technical problems with the eye-tracking device. All these participants were replaced to complete the Latin square design of the experiment. None of the twelve remaining participants had to be excluded on the basis of the digit naming results (mean error rate: $4.2 \%$ ).

\section{Materials}

The same stimulus materials as in Experiment 2 were used. Additionally, 30 digits ( $10 \%$ of the word trials) between 1 and 9 were randomly intermixed in the EM condition. The 2 (display type: EM vs. EPC) x 6 (fixation position 1, 2, 3, 4, 5 or 6 ) design was also identical to that of Experiment 2.

\section{Apparatus}

The same eye-tracking device and settings as in Experiment 2 were used. One adjustment was made with respect to the task in the EPC condition: By covering the left 
eye with an eye patch, we forced the participants to view with their dominant right eye only, which was being tracked.

\section{Procedure}

Experimental procedure, stimulus presentation, and trial outline were identical to the settings of Experiment 2. Instructions in the EM condition were adjusted with the additional information that there would also appear a digit from time to time that had to be named. Participants were informed that they could earn extra money by naming 24 out of the 30 digits correctly.

\section{Results}

Prior to the analyses, data from five categories of inaccuracies were removed: (1) incorrect responses (1.5\%); (2) RTs shorter than $200 \mathrm{~ms}$ or longer than $1500 \mathrm{~ms}$ and inadequate voice key registrations (1.5\%); (3) RTs above or below 2.5 SDs from the mean RT of a participant's condition $(2.7 \%)$; (4) trials on which the first fixation was shorter than $150 \mathrm{~ms}$ (i.e. the duration of stimulus presentation) in the EPC condition (1.3\%); and (5) trials on which inadequate calibration settings had to be corrected $(0.4 \%)$.

Eye fixation analysis. The data of the eye fixation analysis were calculated in the same way as in Experiment 2. Figure 6 shows the results. In the EM condition, participants fixated on $36.4 \%$ of the trials between the boundaries of the letter presented in the gap between the fixation lines. In the EPC condition, this increased to $71.7 \%$. Again, a leftward bias was observed, particularly in the EM condition: $36.9 \%$ of the fixations in this condition fell on letter position -1 , in contrast to $12.4 \%$ fixations on letter position +1 . Mean misfixation distance from letter position 0 was -0.68 letters or $0.19^{\circ}$ in the EM condition and +0.05 letters or $+.01^{\circ}$ in the EPC condition.

As in Experiment 2, many deviations straddled the border between letter positions -1 or +1 and 0 . If we enlarged the boundaries of the critical fixation area by 0.5 letters, fixation accuracy increased to $96.8 \%$ in the EPC condition and to $66.2 \%$ in the EM condition. 


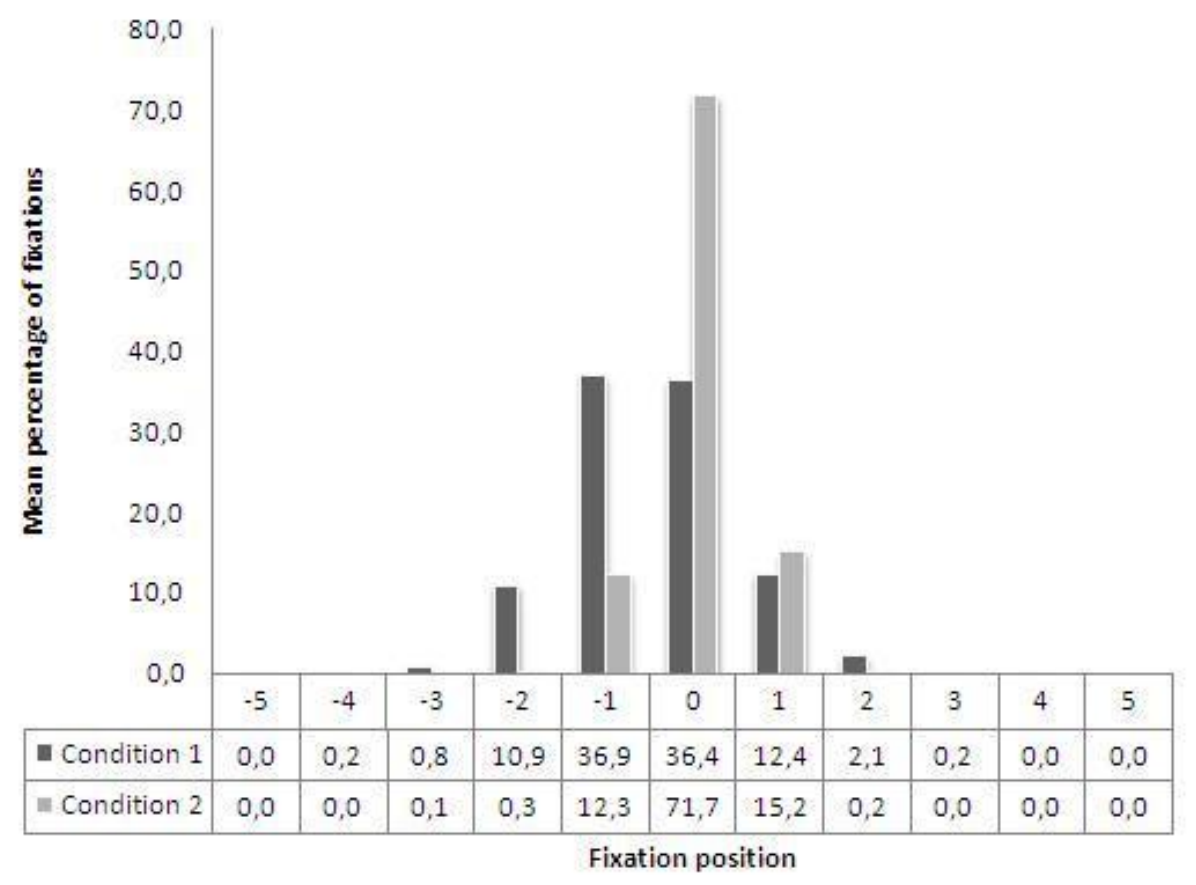

FIGURE 6. Percentages fixation positions at the different letter positions for the two conditions in Experiment 3

Note. Letter position $-5=$ the leftmost possible fixation position, $0=$ the fixation position between the vertical fixation lines, $5=$ the rightmost possible fixation position; Condition $1=$ eye-monitoring condition; Condition 2 = eye position contingent condition; one letter subtends $0.27^{\circ}$

Reaction time analysis. Repeated measures analyses of variance (ANOVA) were run by participants $(\mathrm{F} 1)$ and by items $(\mathrm{F} 2)$. Within variables were fixation position (6 levels: at letter 1, 2, 3, 4, 5 or 6) and display type (2 levels: EM vs. EPC). ANOVAs were conducted with log-transformed RTs to reduce the positive skew in the distribution. Wherever the assumption of sphericity was violated, Greenhouse-Geisser corrections are reported.

The latencies ANOVA indicated a main effect of display type $[F 1(1,11)=21.04$, $M S E=.0060, p<.01 ; F 2(1,274)=613.49, M S E=.0049, p<.001]:$ mean latencies in the EPC condition $(629 \mathrm{~ms})$ were higher than in the EM condition (544 ms). The data also showed a significant main effect of fixation position $[F 1(3.01,33.13)=17.83, M S E$ $=.00037, p<.001 ; F 2(4.72,1293.09)=13.15, M S E=.0079, p<.001]$ : latencies at 
position $3(571 \mathrm{~ms})$ were the fastest, whereas latencies at position $6(618 \mathrm{~ms})$ were the slowest. The interaction between fixation position and display type was not significant $(F \mathrm{~s}<1)$.

Figure 7 shows the OVP curves of the EM and EPC condition in Experiment 3, together with the OVP curve from Experiment 1. Again, the shape of the OVP curves were very similar, as indicated by the non-significant interactions between fixation position and Experiment. A repeated measures ANOVA with fixation position (6 levels: position 1, 2, 3, 4, 5 or 6) and experiment (3 levels: Experiment 1, Experiment 2 EPC and Experiment 3 EPC) as between variable confirmed this similarity. The interaction between fixation position and experiment was not significant $\left(F_{\mathrm{S}}<1\right)$.

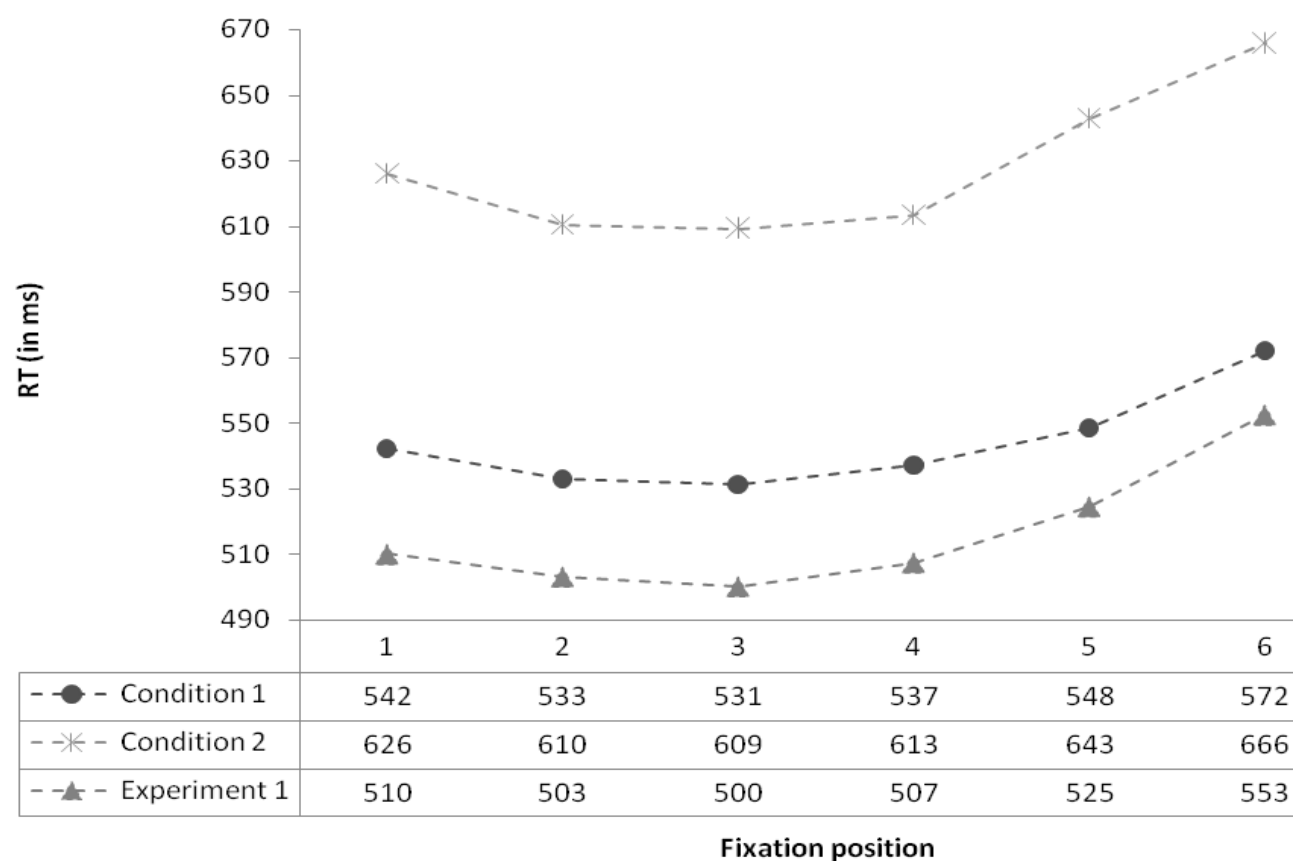

FIGURE 7. Mean response times for the word naming task at the six possible fixation positions in Experiment 1 and in the two conditions of Experiment 3 (EM = eye-monitoring with binocular vision; $\mathrm{EPC}=$ eye position contingent stimulus presentation with monocular vision).

Error analysis. Mean percentages of error rates were $0.5 \%, 0.8 \%, 0.7 \%, 0.3 \%$, $0.5 \%$ and $1.3 \%$ in the EM condition, and $1.7 \%, 1.2 \%, 1.0 \%, 1.0 \%, 2.2 \%$ and $6.4 \%$ in the EPC condition for fixation positions 1, 2, 3, 4, 5 and 6 respectively. ANOVAs on the error rates revealed a main effect of display type $[F 1(1,11)=10.73, M S E=.00084$, 
$p<.01 ; F 2(1,572)=30.04, M S E=.014, p<.001]$. Error rates were higher in the EPC condition $(2.2 \%)$ than in the EM condition $(0.8 \%)$. The main effect of fixation position was also significant $[F 1(1.86,20.48)=8.38, M S E=.0011, p<.01 ; F 2(3.54,2026.40)=$ $11.63, M S E=.020, p<.001]$, with the lowest error rate at fixation position $4(0.7 \%)$ and the highest error rate at fixation position 6 (3.9\%). However, there was also a significant interaction between fixation position and display type $[F 1(2.11,23.24)=$ $6.30, M S E=.00075, p<.01 ; F 2(3.56,2037.49)=6.27, M S E=.021, p<.001]$. In the EM condition, error rates ranged from $0.3 \%$ (position 4) to $1.3 \%$ (position 6); in the EPC condition, error rates ranged from $1.0 \%$ (positions 3 and 4 ) to $6.4 \%$ (position 6).

\section{Discussion}

In Experiment 3, three changes to the usual OVP design were made to meet the objections raised by Jordan et al. (2008; 2009). First, the stimuli were presented within the foveal area. Second, eye-tracking was used to control the fixation accuracy. Third, monocular vision was used to exclude the possibility of fixation disparities between the eyes affecting the data.

As in Experiment 2, the effect on the OVP curve was minimal and nonsignificant. The difference in response latency between fixation on the first letter and fixation on the last letter was $30 \mathrm{~ms}$ in the EM condition and $40 \mathrm{~ms}$ in the monocular EPC condition (compared to a difference of $43 \mathrm{~ms}$ in Experiment 1). Again the OVPcurve tended to be flatter in the EM condition than in the EPC condition, in line with the idea that variation in the fixation positions adds noise to the curve.

Although the OVP curves in the different conditions were very similar, there were consistent variations in the overall RTs. In general, adding a digit fixation control to the OVP paradigm seems to involve a time and error cost (compare the EM condition of Experiment 2 - without digit fixation control - with Experiment 1 and the EM condition of Experiment 3 - with fixation control). The same is true for the registration of eye movements (compare the EM condition of Experiment 3 with Experiment 1), the use of eye position contingent stimulus presentation (compare the EM and EPC 
conditions of Experiments 2 and 3), and the use of monocular viewing (compare the EPC condition of Experiment 3 with the EPC condition of Experiment 2). So, whereas the Leicester objections do not change the OVP curve, they do make the task considerably harder for the participants. Even more than in Experiment 2, the participants did not like the EPC condition of Experiment 3 with monocular viewing. We lost 3/16 participants due to performance problems.

In the EM condition, we additionally examined the effect of the secondary digit fixation control task, used in Experiment 1 and in the previous OVP studies. Overall, the influence of this task in the current experiment was minimal: with strict boundaries only $36.4 \%$ of the trials in Experiment 3 were correctly fixated, compared to $34.4 \%$ in Experiment 2. The outcome was slightly better when boundaries of plus or minus 1.5 letter positions were used: Then, accuracy increased to $66.2 \%$ in Experiment 3, compared to $61.9 \%$ in Experiment 2. Nevertheless, we still observed a leftward fixation bias in both experiments and the scatter in the fixation data was comparable. In this regard, it must be taken into account, though, that performance was quite good in Experiment 2. As mentioned in the Method section of Experiment 1, Van der Haegen et al. (2009) had to exclude nearly half of their participants because they failed to identify enough digits. Only when they were paid for good performance, did they perform properly. So, although the digit fixation control task does not guarantee that the participants will look at the exact fixation location, it arguably does help to detect participants with deviations of more than one letter position. A way to further improve the utility of the digit fixation control task may be to decrease the presentation time of the digits. The current digit naming task was not experienced as difficult by the participants; indeed they performed at ceiling level. It can be expected that the harder the digit task, the more carefully participants will have to look between the fixation lines. At the same time, it will make the task harder, without much effect on the shape of the OVP curve.

General discussion 
In recent years, a group of researchers at the University of Leicester (Jordan \& Paterson, 2009; Jordan et al., 2008, 2009) have strongly criticized research on the Split Fovea Theory (SFT), including the findings of Brysbaert and colleagues with the Optimal Viewing Position (OVP) paradigm. The core of the criticism is that all findings interpreted as evidence for a split fovea could be confounds of inadequate fixation control. This critique continues an objection Jordan and colleagues previously raised against VHF experiments (e.g., Jordan et al., 1998), but which they were unable to substantiate in a study directly comparing free vision with tight fixation control on the basis of an eye-tracker (Jordan \& Patching, 2005).

The present study is an attempt to assess the impact of inadequate fixation control on the OVP effect, in particular on the left-right asymmetry between fixations on the word beginning and the word end, which has been interpreted as evidence for interhemispheric transfer in foveal word recognition (Brysbaert, 1994a; Hunter et al., 2007).

According to Jordan and colleagues, the existing evidence for a split fovea is flawed for four reasons: (1) participants' eye fixations have not been controlled adequately; (2) stimulus sizes exceeded the foveal area or were too small to ensure adequate fixation control; (3) binocular viewing may have contaminated the measurement of precise fixation position; and (4) tasks such as naming are inappropriate. Three experiments were run to evaluate the first three objections (see below for our response to the last objection).

In our experiments, using free vision, monitored vision, and eye position controlled stimulus presentation with binocular and monocular vision, we found that (1) there is indeed some scatter in the fixation positions of the participants from trial to trial (Figures 4 and 6); (2) in the OVP paradigm with word naming there is a bias towards fixations slightly to the left of the required position (Figures 4 and 6); (3) these deviations are not much improved by requiring participants to do a secondary digit identification task on a limited number of trials; and (4) the deviations add noise to the OVP curve, but do not change the curve in such a way that the SFT is called into 
question. If anything, the OVP-effect becomes stronger when accurate fixation is ensured (Figures 5 and 7), but this has a nonneglegible cost on the participants' performance and their comfort. ${ }^{5}$

Now that we know the empirical data, we are in a better position to theoretically evaluate the specific objections made. As indicated, the core issue identified by Jordan and colleagues is that inadequate fixation control calls into question all existing evidence in favor of the SFT, including the research based on the OVP effect. Importantly, Jordan et al. have never put forward a mechanism to explain how inadequate fixation control could give rise to the difference in OVP curve observed between left dominant and right dominant participants (Figure 2); all they argued was that the data were suspect. It is not easy to find a mechanism that on the basis of inadequate fixations could lead to a strong left-right asymmetry in participants with left hemisphere dominance and to a flat curve in participants with right hemisphere dominance. The only one we were able to find was Kinsbourne's (1970) theory of lateral asymmetries in attention allocation. According to this theory, when one hemisphere is active attention is shifted to the contralateral VHF. Assuming that there is a fixation bias towards the attended VHF, this theory could predict that left dominant participants show a systematic fixation bias towards RVF while naming words, whereas right dominant participants show a systematic shift towards LVF. As a result, the leftright asymmetry in word processing would be enhanced in left dominant participants and attenuated in right dominant participants. Needless to say, this interpretation is completely at odds with our empirical data. Not only does the OVP curve stay the same under tight fixation control, we also observe a fixation bias in the opposite direction to the one predicted by Kinsbourne's theory: left hemisphere dominant participants have a bias towards LVF not towards RVF, presumably because fixations slightly to the left of the required location improve the overall performance (see the discussion of Experiment 2).

\footnotetext{
${ }^{5}$ The cost can also be illustrated with the results of Jordan et al. (2009). In their third experiment, lexical decision times for words were on average $807 \mathrm{~ms}$ for five-letter stimuli and $888 \mathrm{~ms}$ for eight-letter stimuli. Mean error rates were between 18\% (five-letter words) and 23\% (eight-letter words), much worse than what is usually reported in psycholinguistic studies.
} 
A much simpler hypothesis is that the lack of fixation control in OVP experiments introduces trial-to-trial noise, making the OVP curve slightly flatter than it could be under optimal circumstances (because participants sometimes fixate at position -1 or +1 , while the experimenters assume them to be on position 0 ). This hypothesis is fully in line with our findings and, as it happens, with some of Jordan's own previous work (Jordan \& Patching, 2005).

A second objection, related to the first, is that fixation disparities between the left and the right eye might somehow confound the OVP curve. Again, no mentioning has been made of possible mechanisms. Only suspicion was raised on the basis of findings in text reading. As before, we failed to find any corroborating evidence: The OVP effect was in all relevant aspects the same under monocular viewing conditions as under binocular viewing conditions.

This leaves us with two remaining criticisms that have been raised against the interpretation of the OVP effect as influenced by interhemispheric transfer. The first is that the stimuli in most experiments were too wide, exceeding the region of 'bilateral projection'. We have addressed this concern in Experiments 2 and 3 by limiting the size of the words to $1.5^{\circ}$. Given that we did not observe any difference with the data of Experiment 1 or with previous experiments, we can safely conclude that the alleged bilateral projection does not include the $3^{\circ}$ often claimed. A more tricky question is whether it could be smaller, say only $1^{\circ}$. We admit that the present studies cannot convincingly refute this possibility. This can only be done by comparing the OVP effect of left and right hemisphere dominant participants for very short words (of 3 and 4 letters). Such studies have been reported by Brysbaert (1994a) and Hunter et al. (2007) with the expected difference between the left and the right dominant participants, but these studies did not involve fixation control and they were based on binocular vision. All we can say at the moment is that an overlap of $0.5^{\circ}$ to either side of the fixation location does not really change the underlying issue, as it implies that centrally fixated words longer than 5 letters require interhemispheric communication to be processed. The most appealing aspect of a bilaterally projecting fovea indeed was that it discharged 
researchers of visual word recognition from having to consider the anatomical divide between the brain halves in their theories at all.

Finally, there is the criticism that the naming task might be an inappropriate task because it is too lateralized. The reasoning here is that visually presented words can be processed bilaterally but require the dominant hemisphere to be pronounced. This is exactly the reason why we have been using the naming task, because the laterality of Broca's area is easy to establish with the current brain imaging techniques. Knecht, Deppe, Ebner, Henningsen, Huber, Jokeit, and Ringelstein (1998) showed that laterality measures based on differences in blood flow to the left and the right frontal cortex during a word generation task are perfectly correlated with the best available clinical tool to determine language dominance, the WADA test. Jordan and colleagues object against the word naming task, because the differences between left and right dominant participants on this task seem to imply that visual word recognition entirely depends on the dominant hemisphere, whereas in reality the lateralization may be limited to the word production part (Broca's area).

We agree that the OVP naming task only tells us something about the need for interhemispheric transfer in speech production. However, we fail to see how this could be an argument against the split-fovea theory. SFT does not claim that all word processing is limited to the dominant hemisphere. It only says that interhemispheric communication is needed for the processing of centrally fixated words. It also argues that this communication in healthy participants has a time cost long enough to be measurable (typically in the order of 10-20 ms depending on the length of the word) and that the requirement of interhemispheric transfer predicts problems for people with a severed corpus callosum, such as split-brain patients and individuals with callosal agenesis. A bilateral account of foveal processing would predict no differences in the naming pattern of right and left dominant participants, as no transfer is needed. However, studies as Brysbaert (1994a) and Hunter et al. (2007) did observe a time cost when comparing the OVP curves of both groups. The naming task is perfectly suited to measure the need for interhemispheric communication. Other techniques (fMRI, MEG) are much more appropriate to study the laterality of the word processes in the temporal 
cortex (see, e.g., Cai, Lavidor, Brysbaert, Paulignan, \& Nazir, 2008; Cohen, Dehaene, Naccache, Lehericy, Dehaene-Lambertz, Henaff, \& Michel, 2000; Gold \& Rastle, 2007).

The limits of the objection against the naming task can be compared with the problems related to the task favored by the Leicester group. Their task of choice is the Reicher-Wheeler task (e.g., Jordan et al., 2008b). In this task participants see tachistocopically presented words and have to indicate which letter was presented at a given position. For instance, the stimulus "snow" is flashed for a few milliseconds and participants have to indicate whether the letter " $n$ " or " $h$ " was presented at the second position. Typically, stimulus presentation time is limited to ensure some $66 \%$ correct identification. Using this task, Jordan et al. (2008) showed that participants performed better with presentation in RVF than in LVF when parafoveal presentation was used (more than $2^{\circ}$ away from the fixation location), but not when foveal vision was used (less than $.5^{\circ}$ from the fixation location). On the basis of this finding, Jordan et al. claimed to have evidence for a bilateral representation of the central $1^{\circ}$ of the visual field. They additionally claimed that their result questioned all existing evidence for SFT (because it had failed to take into account proper fixation control, etc.).

We do not question Jordan et al.'s (2008) finding. We simply notice that the Reicher-Wheeler task is an offline task, in which conclusions are drawn on the basis of accuracy data. There is big difference between saying that interhemispheric transfer requires some 10-20 ms extra in healthy participants (which can be measured in carefully designed studies) and claiming that the extra time cost must result in a drop of performance accuracy. Offline tasks based on accuracy data are most interesting when there is evidence for suboptimal processing, for instance in the case of split-brain patients. They are a crude measure when it comes to study the fine-grained, online processes involved in normal word recognition. High accuracy in the Reicher-Wheeler task can be reached on the basis of correct perceptual identification instead of recognition at word level (Grainger \& Jacobs, 1994) and can thus reflect other processes than we intend to measure. Jordan et al. (2008) counter this criticism by pointing to the clear difference between the parafoveal LVF and RVF conditions, showing that the 
technique is capable of picking up this effect. Unfortunately, the most likely interpretation of the difference between parafoveal LVF presentation on the one hand and foveal presentation or parafoveal RVF presentation on the other hand is that English reading participants have virtually no practice recognizing words in parafoveal LVF vision. One of the consequences of this difference in practice is that words in LVF parafoveal vision are processed much less in parallel than words presented in foveal or RVF parafoveal vision (Nazir, Ben-Boutayab, Decoppet, Deutsch, \& Frost, 2004).

All in all, we agree that reasonable confounds must be checked. This is why we invested heavily in the current series of experiments. At the same time, it cannot be denied that the benefits of experimental control follow an inverted $U$ shaped curve with an optimal value somewhere in the middle: not enough control is bad, but too much control is counterproductive as well. Given the present findings, we hope the Leicester group will agree with us that for a valid OVP study it is not required to fully immobilize participants by means of a bite bar and a headrest, to continuously monitor their eyes with two dual-Purkinje eye-trackers, and to present the stimuli only when both eyes are exactly on the indicated spot of the computer screen. Indeed, Jordan and Patching's (2005) findings remind us that initially justified concerns about confounds need not imply that all previous research was invalid, just that the validity of the findings must be assessed properly. 


\section{References}

Baayen, R., Piepenbrock, R., \& Van Rijn, H. (1993). The CELEX lexical database. [CD-ROM]. Philadelphia: University of Pennsylvania: Linguistic Data Consortium.

Brysbaert, M. (1994a). Interhemispheric transfer and the processing of foveally presented stimuli. Behavioural Brain Research, 64, 151-161.

Brysbaert, M. (1994b). Lateral preferences and visual field asymmetries: Appearances may have been overstated. Cortex, 30, 413-429.

Brysbaert, M. (2004). The importance of interhemispheric transfer for foveal vision: A factor that has been overlooked in theories of visual word recognition and object perception. Brain and Language, 88, 259-267.

Brysbaert, M., \& Nazir, T. (2005). Visual constraints in written word recognition: evidence from the optimal viewing-position effect. Journal of Research in Reading, 28, 216-228.

Brysbaert, M., Vitu, F., \& Schroyens, W. (1996). The right visual field advantage and the optimal viewing position effect: On the relation between foveal and parafoveal word recognition. Neuropsychology, 10, 385-395.

Bunt, A.H., Minckler, D.S., \& Johanson, G.W. (1977). Demonstration of bilateral projection of the central retina of the monkey with horseradish peroxidase neuronography. Journal of Comparative Neurology, 171, 619-630.

Cai, Q., Lavidor, M., Brysbaert, M., Paulignan, Y., \& Nazir, T.A. (2008). Cerebral lateralization of frontal lobe language processes and lateralization of the posterior visual word processing system. Journal of Cognitive Neuroscience, 20, 672-681.

Cohen, L., Dehaene, S., Naccache, L., Lehericy, S., Dehaene-Lambertz, G., Henaff, M.A., \& Michel, F. (2000). The visual word form area: Spatial and temporal characterization of an initial stage of reading in normal subjects and posterior split-brain patients. Brain, 123, 291-307.

Duyck, W., Desmet, T., Verbeke, L., \& Brysbaert, M. (2004). Wordgen: A Tool for Word Selection and Non-Word Generation in Dutch, German, English, and French. Behavior Research Methods, Instruments \& Computers, 36, 488-499. 
Ellis, A.W., Brooks, J., \& Lavidor, M. (2005). Evaluating a split fovea model of visual word recognition: effects of case alternations in the two visual fields and in the left and right halves of words presented at the fovea. Neuropsychologia, 43, $1128-1137$.

Gazzaniga, M.S. (2000). Cerebral specialization and interhemispheric communication: Does the corpus callosum enable the human condition? Brain, 123, 1293-1326.

Gold, B.T., \& Rastle, K. (2007). Neural correlates of morphological decomposition during visual word recognition. Journal of Cognitive Neuroscience, 19, 19831993.

Grainger, J., \& Jacobs, A.M. (1994). A dual read-out model of word context effects in letter perception: Further investigations of the word superiority effect. Journal of Experimental Psychology: Human Perception and Performance, 20, 1158-1176.

Harvey, L.O. (1978). Single representation of visual midline in humans. Neuropsychologia, 16, 601-610.

Haun, F. (1978). Functional dissociation of the hemispheres using foveal visual input. Neuropsychologia, 16, 725-733.

Hunter, Z.R., \& Brysbaert, M. (2008a). Theoretical analysis of interhemispheric transfer costs in visual word recognition. Language and Cognitive Processes, 23, 165182.

Hunter, Z.R., \& Brysbaert, M. (2008b). Visual half-field experiments are a good measure of cerebral language dominance if used properly: Evidence from fMRI. Neuropsychologia, 46, 316-325.

Hunter, Z.R., Brysbaert, M., \& Knecht, S. (2007). Foveal Word Reading Requires Interhemispheric Communication. Journal of Cognitive Neuroscience, 19, 13731387.

Jordan, T.R., \& Patching, G.R. (2005). Assessing effects of fixations demands on perception of lateralized words: A visual window technique for studying hemispheric asymmetry. Neuropsychologia, 44, 686-692.

Jordan, T.R., Patching, G.R., \& Milner, A.D. (1998). Central fixations are inadequately controlled by instructions alone: Implications for studying cerebral asymmetry. Quarterly Journal of Experimental Psychology Section A - Human Experimental Psychology, 51, 371-391. 
Jordan, T.R., \& Paterson, K.B. (2009). Re-evaluating split-fovea processing in word recognition: A critical assessment of recent research. Neuropsychologia, 47, 2341-2353.

Jordan, T.R., Paterson, K.B., \& Stachurski, M. (2008). Re-evaluating split-fovea processing in word recognition: Effects of retinal eccentricity on hemispheric dominance. Neuropsychology, 22, 738-745.

Jordan, T.R., Paterson, K.B., \& Stachurski, M. (2009). Re-evaluating split-fovea processing in word recognition: Effects of word length. Cortex, 45, 495-505.

Kinsbourne, M. (1970). Cerebral basis of lateral asymmetries in attention. Acta Psychologica, 33, 193-201.

Kirkby, J.A., Webster, L.A.D., Blythe, H.I., \& Liversedge, S.P. (2008). Binocular coordination during reading and non-reading tasks. Psychological Bulletin, 134, $742-763$.

Knecht, S., Deppe, M., Ebner, A., Henningsen, H., Huber, T., Jokeit, H., \& Ringelstein, E.B. (1998). Noninvasive determination of language lateralization by functional transcanial Doppler sonography: A comparison with the WADA test. Stroke, 29, $82-86$

Knecht, S., Dräger, B., Deppe, M., Bobe, L., Lohmann, H., Floel, A., et al. (2000). Handedness and hemispheric language dominance in healthy humans. Brain, $123,2512-2518$.

Lavidor, M., \& Walsh, V. (2004). The nature of foveal representation. Nature Reviews Neuroscience, 5, 729-735.

Lavidor, M., Ellis, A.W., Shillcock, R., \& Bland, T. (2001). Evaluating a split processing model of visual word recognition: Effects of word length. Cognitive Brain Research, 12, 265-272.

Martin, C.D., Thierry, G., Démonet, J.F., Roberts, M., \& Nazir, T. (2007). ERP evidence for the split fovea theory. Brain Research, 1185, 212-220.

Miles, W.R. (1930). Ocular dominance in human adults. Journal of General Psychology, 3, 412-420.

Nazir, T.A., Ben-Boutayab, N., Decoppet, N., Deutsch, A., \& Frost, R. (2004). Reading habits, perceptual learning, and recognition of printed words. Brain and Language, 88, 294-311. 
Oldfield, R.C. (1971). The assessment and analysis of handedness: The Edinburgh inventory. Neuropsychologia, 9, 97-113.

O’Regan, J.K., \& Jacobs, A.M. (1992). Optimal Viewing Position Effect in Word Recognition: A Challenge to Current Theory. Journal of Experimental Psychology: Human Perception and Performance, 18, 185-197.

Porac, C., \& Coren, S. (1976). The dominant eye. Psychological Bulletin, 83, 880-897.

Porac, C., \& Coren, S. (1981). Lateral preferences and human behavior. New York: Springer-Verlag.

Rayner, K., \& Pollatsek, A. (1989). The psychology of reading. Englewood Cliffs, NJ: Prentice-Hall.

Van der Haegen, L., Brysbaert, M., \& Davis, C.J. (2009). How does interhemispheric communication in visual word recognition work? Deciding between early and late integration accounts of the split fovea theory. Brain and Language.

Whitney, C. (2001). How the brain encodes the order of letters in a printed word: The SERIOL model and selective literature review. Psychonomic Bulletin \& Review, 8, 221-243. 
Appendix

Stimuli used in Experiments 1, 2 and 3

\begin{tabular}{|c|c|c|c|c|c|}
\hline aanbod & bekken & charme & etiket & gevoel & honger \\
\hline aanpak & beklag & cinema & etmaal & gevolg & honing \\
\hline aantal & belang & circus & examen & geweer & hoogte \\
\hline aanval & beleid & cirkel & excuus & geweld & hostie \\
\hline aanzet & bereik & citaat & expert & gewelf & humeur \\
\hline accent & beroep & climax & export & gewest & ideaal \\
\hline acteur & berouw & cognac & factor & gezang & idioot \\
\hline advies & bestek & crisis & fakkel & gezant & ijskap \\
\hline afdruk & betoog & cultus & fazant & gezwel & import \\
\hline afkeer & beugel & cyclus & fiasco & gieter & impuls \\
\hline afloop & bezoek & dakpan & figuur & gitaar & indruk \\
\hline agenda & biecht & daling & filter & glorie & infuus \\
\hline altaar & bijbel & danser & finale & gordel & ingang \\
\hline amulet & biljet & dealer & fiscus & gracht & inhoud \\
\hline antiek & bisdom & debuut & flater & gratie & inkoop \\
\hline arbeid & blazer & deksel & fokker & gravin & invoer \\
\hline arrest & bochel & delict & folder & grijns & ironie \\
\hline asfalt & boeket & deling & franje & grimas & jargon \\
\hline aspect & boerin & denker & garage & groeve & jarige \\
\hline attest & bokaal & detail & gebaar & gruwel & jaszak \\
\hline augurk & bokser & dienst & gebied & handel & jongen \\
\hline auteur & borrel & diepte & gebouw & hangar & jungle \\
\hline badjas & budget & docent & gebrek & haring & junior \\
\hline bagage & buffel & dokter & gebrul & harnas & jurist \\
\hline bakker & buffer & domein & gedrag & heelal & kabaal \\
\hline balans & buffet & donder & geduld & heldin & kachel \\
\hline balkon & buidel & doping & geheel & helium & kajuit \\
\hline ballet & bumper & douane & geheim & hendel & kalmte \\
\hline ballon & bundel & douche & gehoor & hengel & kameel \\
\hline balpen & bunker & dozijn & gehuil & hengst & kanaal \\
\hline balsem & burcht & dracht & gelaat & herder & kaneel \\
\hline bamboe & burger & duivel & geloof & herfst & kanker \\
\hline banaan & butler & editie & geluid & herrie & kanton \\
\hline barman & cabine & effect & gember & hertog & kapper \\
\hline bassin & cactus & eiland & gemoed & heuvel & kapsel \\
\hline bedrag & cadeau & ekster & gerant & hinder & karper \\
\hline bedrog & camera & embryo & geroep & hippie & kartel \\
\hline behang & casino & eskimo & geruis & hoepel & karton \\
\hline beitel & cement & etappe & gevaar & hommel & karwei \\
\hline
\end{tabular}




\begin{tabular}{|c|c|c|c|c|c|}
\hline katoen & leegte & monnik & opstel & ravijn & schoot \\
\hline keizer & leider & moraal & optiek & recept & schors \\
\hline kelder & lemmet & morgen & opvang & rechte & schort \\
\hline kelner & lengte & mortel & orakel & record & schouw \\
\hline kennis & lening & moskee & orgaan & rector & schram \\
\hline kerker & lesuur & moslim & orkaan & redder & schrik \\
\hline kermis & letsel & mossel & orkest & reflex & schuim \\
\hline ketter & letter & motief & pagina & regime & schuld \\
\hline keuken & leugen & muziek & pakket & reiger & schuur \\
\hline kiezer & lezing & nadeel & paleis & relaas & script \\
\hline kikker & liefde & nadruk & paling & ridder & sectie \\
\hline klacht & lifter & najaar & paneel & rimpel & sector \\
\hline klasse & likeur & natuur & paniek & risico & selder \\
\hline klaver & limiet & nieuws & panter & rivaal & senaat \\
\hline kledij & logica & nikkel & papier & rivier & senior \\
\hline klepel & lokaal & niveau & paraaf & robijn & servet \\
\hline klimop & maffia & noemer & parfum & roddel & sigaar \\
\hline knecht & makker & nonkel & parket & rommel & sikkel \\
\hline koelte & manier & nuance & partij & rozijn & sirene \\
\hline koepel & mantel & nummer & passie & rubber & siroop \\
\hline koffer & marine & object & patent & rugzak & skelet \\
\hline koffie & marmer & oceaan & pedaal & ruiker & slager \\
\hline kokkin & masker & oester & pendel & ruimte & slavin \\
\hline komeet & matras & omelet & perron & ruiter & slogan \\
\hline kompas & medium & omgang & perzik & rumoer & sluier \\
\hline konijn & meisje & omloop & peuter & salade & sneeuw \\
\hline koning & meloen & omroep & pijler & satijn & solist \\
\hline koorts & meneer & omslag & piloot & satire & specht \\
\hline koppel & mening & omtrek & pincet & schaal & speler \\
\hline koraal & mentor & omvang & piraat & schaap & spleet \\
\hline korrel & merrie & onheil & plicht & schaar & spraak \\
\hline kosmos & metaal & onraad & podium & schade & spreuk \\
\hline koster & meting & onrust & poedel & schelp & sprint \\
\hline kracht & meubel & onweer & poeder & scherf & sproet \\
\hline krater & middag & oorbel & poging & scherm & spruit \\
\hline kreeft & middel & oorlog & polder & schets & staart \\
\hline kromme & midden & oosten & portie & scheur & stapel \\
\hline kroost & milieu & opbouw & poster & scheut & status \\
\hline kuiken & minuut & opgave & pracht & schijf & stekel \\
\hline laagte & modder & opinie & premie & schijn & steppe \\
\hline ladder & moeder & oplage & proces & schild & stilte \\
\hline lawaai & moeite & opmars & puzzel & schoen & straal \\
\hline lawine & moeras & opname & radijs & schoft & straat \\
\hline lector & moment & opslag & ravage & school & strand \\
\hline
\end{tabular}




$\begin{array}{llllll}\text { streek } & \text { tarief } & \text { trauma } & \text { vergif } & \text { vracht } & \text { wissel } \\ \text { streep } & \text { tehuis } & \text { triomf } & \text { verlof } & \text { vriend } & \text { wonder } \\ \text { strijd } & \text { tempel } & \text { troost } & \text { vernis } & \text { vrucht } & \text { woning } \\ \text { strijk } & \text { tennis } & \text { tumult } & \text { verval } & \text { vulpen } & \text { wortel } \\ \text { strofe } & \text { terras } & \text { tuniek } & \text { verzet } & \text { waaier } & \text { wrevel } \\ \text { stronk } & \text { teugel } & \text { tunnel } & \text { vijand } & \text { waarde } & \text { zakmes } \\ \text { strook } & \text { ticket } & \text { turner } & \text { vijver } & \text { walvis } & \text { zender } \\ \text { stroom } & \text { tiener } & \text { uiting } & \text { viking } & \text { weelde } & \text { zijweg } \\ \text { stroop } & \text { tijger } & \text { uitleg } & \text { vinger } & \text { wegdek } & \text { zilver } \\ \text { struik } & \text { toeval } & \text { uitval } & \text { visser } & \text { wekker } & \text { zolder } \\ \text { studie } & \text { tomaat } & \text { utopie } & \text { vizier } & \text { wereld } & \text { zondag } \\ \text { studio } & \text { toneel } & \text { vakman } & \text { vlakte } & \text { westen } & \text { zuiden } \\ \text { succes } & \text { tonijn } & \text { vallei } & \text { vlecht } & \text { wijzer } & \text { zuivel } \\ \text { suiker } & \text { toorts } & \text { vangst } & \text { vlucht } & \text { wimpel } & \text { zuster } \\ \text { sultan } & \text { totaal } & \text { varken } & \text { volume } & \text { wimper } & \text { zwaard } \\ \text { taille } & \text { tralie } & \text { venkel } & \text { vondst } & \text { winkel } & \text { zwakte } \\ \text { tapijt } & \text { trance } & \text { verbod } & \text { vonnis } & \text { winter } & \text { zwaluw }\end{array}$

